\title{
Investigation of Social Approaches in Different Countries towards Suicide of the Blue Whale Game through Newspaper News
}

\author{
By Ayşe Aslı Sezgin *
}

\begin{abstract}
The aim of this study is to examine the negative attitude and prejudice of the media reflected in news articles about the relationship between 'online games and suicidal youth'. This study analyzed the content of the news and the language of the media used for young people who committed suicide related to playing Blue Whale Challenge in different social settings. In this study, news articles in three different countries were examined with the content analysis method, using the content descriptors of Entertainment Software Rating Board (ESRB). In the news concerning young people who committed suicide and used this game, it was clearly observed that sources of influence involved attitudes towards online games, developed in part through the messages of the media, and that social conditions, including generational experiences, were influential in creating the media messages.
\end{abstract}

Keywords: media panic, violence, online games, Blue Whale Challenge

\section{Introduction}

Intergenerational differences have been an important subject of academic inquiry in the field of social sciences. Recent studies (Yang, 2008; Alwin, 2002; Jorgensen, 2003; Huang and Petrick, 2010) have classified generations as X, Y and $\mathrm{Z}$, according to the chronological order. The concept of cohorts refers to generations whose common features come to the fore in the social process.

The term 'cohort', which is often used to describe a group of people born in the same time frame, refers to people with similar age-related experiences and paths in life (Katz, 2017). In defining the generations, the definition of cohorts is, therefore, used with its specific characteristic. The concept of cohorts, which is used as a key concept in studies analyzing social change, refers to groups of different sizes in society, especially depending on age. This concept also indicates that. These groups generally go through the same social experiences (Nilsen, 2014).

In this context, when it comes to conducting a sociological classification, the characteristics of groups defined as Generations X, Y and Z have been highlighted in recent years. In this study, different generations are briefly explained in chronological order.

The main purpose of this study is to draw attention to negative attitudes and prejudices created by media messages on societies. One example of such negative

*Associate Professor, Department of Communication Sciences, Faculty of Communication, Çukurova University, Turkey. 
attitudes is related to the game called Blue Whale Challenge, which is perceived by people as reflected in the media, creating a panic atmosphere throughout the society. Here, the main concern is the media's point of view. For this reason, this study examined the media messages in particular in a variety of social settings. A considerable outcome obtained from the study is that just like the impact of social conditions on the process of creating media messages, social reactions are affected by media messages in a similar manner.

Computer-based online games have been a universal feature of popular culture in recent years. The set-up of reality in these games requires the use of the most complex software, hardware, animation and graphic design technologies with respect to the dramatic and fantastic environment, information and communication technology. Online games enable many people to play through the online network provided by PC communication services. Online games create an environment in which people can interact with each other by using graphics and audio technologies, allowing people to feel the excitement of the game while playing. Defined as games where many people can participate in online communication networks at the same time, online games enable players to interact directly with the game through a server (Hoon et al., 2002). The game called the Blue Whale Challenge is one of those in which interaction is the most intense. However, another important detail is the lack of information about the causes of violence and suicide. The way the media, which is an important source of information on the subject, reflects these events, clearly aims to create a panic atmosphere.

In the study conducted by Lindsay et al. (2014) on the spread of violence in the media content, violence was examined in various media contents. Violence in the media is briefly described as 'a clear depiction of a threat or a force that could harm' (Lindsay et al., 2014).

Additionally, the effect of violence on society was also examined in the same study, which stated that especially children and young people who are exposed to violence in the media content tend to exhibit more aggressive behavior than those who are not. Such young people and children may also get provoked more, depending on the extent of the panic atmosphere created by the media (Lindsay et al., 2014). Violence in the media also affects how people perceive the world and their reactions to events around them. Violence in the media content is also effective in emotional reactions of people when they encounter real violence (Lindsay et al., 2014). In this study, the negative language used for communicating the news about Blue Whale Challenge in the media is examined within the scope of the relationship between the media and violence.

\section{Literature Review}

\section{Generations X, Y and Z Definitions}

Generation X, which took its social aspects from the Baby Boomers, born in the late 1940s and early 1960s, represents those who were born in the late 1970s (Katz, 2017). The characteristics of Generation X can be defined as individuals 
who are autonomous, independent and prone to communication (Jorgensen, 2003). An evaluation made about Generation $X$ in the social context reveals a period in which social movements began to take place. Unlike Baby Boomers, Generation $\mathrm{X}$ represents a generation of families who began to face financial difficulties (Sandeen, 2008).

Furthermore, an important social feature of Generation Y, born between the late 1970s and the late 1980s, is their relationship with technology (Bolton et al., 2013).

Feeling comfortable and happy with the presence of technology, Generation Z refers to an age group that prefers social media to socialize (Strauss and Howe, 1991). This generation, which opts to stay in after the increased global terrorist incidents after the 2000s is also called the 'Homeland Generation' (Howe and Strauss, 2000). Generation $\mathrm{Z}$ is also regarded as a generation that often feels inadequate to survive socially without the opportunities offered by the digital world.

In the studies conducted in the field of social sciences, intergenerational differences are emphasized in order to be able to comprehend the changes experienced by societies. People's perception of what is going on in their surroundings and their world views depend on what they experience in the process of socialization. Thus, different generations have their own common cultural identity in community life that separates them from the other generations (Alwin and McCammon, 2003). Unlike the past generations, Generation Z, standing between the real and virtual, makes friends online, interacting with others and spending their free time in this environment. Online games are among the most preferred activities among this generation (Alwin and McCammon, 2003).

\section{Online Games, Violence and Blue Whale Challenge}

In online games, where players play in different venues by interacting, the users (players) share information in a virtual world via internet connection (Ho and $\mathrm{Wu}, 2012)$. For instance, on a web page, specifically Bahamut, which is one gamebased popular community pages in Taiwan, gamers share information and rate computer/video games and online games. Using this platform, games are commented on and popular games are determined (Hsiao et al., 2015). Furthermore, on this web page, online games are classified into different categories, such as role-playing games, action games, shooting games, sports games, adventure games, puzzle games, and war-strategy games ( $\mathrm{Ho}$ and $\mathrm{Wu}$, 2012).

Hoon et al. (2002) classified various online games into four different categories, specifying the characteristics of the games as follows:

- Role playing games: Games in which roles are performed according to a structured scenario.

- Simulation games: Games that enable the user to go through the experience of a simulation with the help of strategic thinking. 
- $\quad$ MUD (Multiuser Dungeons/Dimensions) games: A text-based game or just social space expressed through writing) (Mortensen, 2006).

- Shooting games: Games focused on shooting a target or targets.

Following the studies conducted on computer and console-based video games, there has been an increase in studies conducted on online games. Online games, which include various features such as creating a competitive environment, socializing and challenging, demonstrate the traces of different cultures and reflections of daily life (Hoon et. al., 2002).

Online games have been discussed in the media in recent years. The focus of these discussions is on the fact that online games generally focus on the themes of violence. Families, politicians, and researchers express their concern that such content will increase anti-social behavior (Przybylski et al., 2009). Autonomy and feelings of competence emerge in online games that involve war or organized crime (Przybylski et al., 2009). In these games, players' choice of combat settings, selecting targets, creating strategies, and enforcing personal control over actions reinforce autonomy and competence. In multiplayer games, players running for a common goal share goals and rewards, thus gaining experience in the field of collaboration (Przybylski et al., 2009). In addition to these characteristics, online games are one of the settings where violence is transmitted through media.

Potter (1999) studied the effects of exposure to violence through media content. The presentation of violence in the media content can lead to the emergence of fear along with depersonalization. The content of violence in the media, which draws our attention to its impact on children, is also effective in perpetuating acts of violence.

In 1993, the video game Streetfighter had such a success that surpassed the proceeds of the box-office hit Jurassic Park. Following such an attention-taking success within the entertainment business, Mortal Kombat, distinguished with its content of violence, was also one of the best-selling games in 1993 (Hall, 2011). In the early 1990s, such developments suggested that the content of violence was demanded in the entertainment industry. However, while explaining the relationship of violence with games, it can be suggested that toys (weapons, knives, soldiers, etc.) with the connotation of war have already been included in children's play long before the video games. On examining traditional children's games played on the street long before online games, we found that they differ in many aspects from online games and video games. One difference is the harm given to other people, albeit in a virtual environment. The scenes of violence repeated countless times in online games and video games enable users to harm others to the extent of killing within the game (Goldstein, 1998).

The social changes that online games have created due to the effects of new media technology on community life have been examined with interest. In particular, the negative effects on an individual's mental health have been the subject of a long debate. As a result of the increasingly widespread use of the Internet, there have been increasingly anxious approaches to online games (Williams and Skoric, 2005). Addiction is one of the prominent topics in studies conducted on the psychological effects of online games. Such studies state that 
especially children and young people are more vulnerable to addiction. Attention is drawn to increased social isolation, depression, and anxiety in becoming addicted to online games (Wang et al., 2019). Online games with violent content are also considered to cause aggressive behavior. It is argued that the higher the sense of reality of these violent games, the more aggressively the players behave (Quwaider et al., 2019).

In responses to armed attacks in high schools in the United States in the early 2000s, Anderson and Bushman (2001) stated that the kids who carried out such attacks were young people who made a habit of playing online games with violent content. Anderson and Bushman (2001), who investigated the effects of violence presented in the media in the model they called General Aggression Model (GAM), have underlined that aggressive behavior largely depends on learning, activation, and application of the structures of knowledge stored in memory.

According to the General Aggression Model, learning, rehearsing and activating the cognitive structures related to aggression causes aggressive behavior. One of the most striking examples of violent and aggressive behavior that spread through online games in recent years has resulted from the game called Blue Whale Challenge. However, an important detail to note here is that there is no concrete evidence of the relationship between violence and online gaming. The important problem here, as this study aims to emphasize, is the role of the media in creating negative prejudice against online games. Media content is very effective in creating a panic atmosphere about online games.

The media can be both the source and the provocative agent of the debates in social life. The way a social issue is communicated through the media can lead to intense emotional reactions and consequences that can be referred to as so-called 'media panic'. In this panic atmosphere, negative aspects are often highlighted. Through the media, moral values are also included especially in discussions involving children and young people. In discussions in such a panic atmosphere where different parties take part, following the beginning part, there appears a section where the discussion is intensified and a conclusion part which indicates the solution (Drotner, 1999). A panic atmosphere begins to emerge as a result of the media's making news out of an issue that is perceived as 'threat' by the society. While an unusual event communicates through the language used by the media, an atmosphere begins to form in such a way that seizes the imagination of people (Welch et al., 2002).

Blue Whale Challenge, which takes its name from the suicidal life of whales that have been known to beach themselves, is a suicide game launched in Russia in 2013. In this game, which involves a series of tasks that must be completed in 50 days, the players are being dragged into an increasingly dangerous and lifethreatening situation. Once the players start the game, they are no longer allowed to leave the game and they perform the tasks under the control of the game masters. The players who take commands such as "Watch a scary movie, listen to music in a disturbing way, try to cut one's arm or leg, cut a whale figure into your arm" try to complete 50 steps, respectively (Adeane, 2019).

Players who receive the commands in the game through social media are selected by the game masters. In the game where there are no applications and the 
messages come from networks such as Whatsapp, Facebook, or Snapchat (Mukhra et al., 2017). Every action of the smart phones is monitored in detail through the link sent to the chosen person. This connection, such as a virus, is a serious threat to personal data by following the user's browsing history, email accounts, passwords, phone book, photos, and videos (Mukhra et al., 2017).

Blue Whale Challenge posed a serious threat online, encouraging its victims to various actions such as watching a scary movie at midnight or self-injury with sharp objects (Mukhra et al., 2017). It appears that online games contain content that tend to encourage harm to others. In the Blue Whale Challenge, however, players are directly encouraged to harm themselves

\section{Methodology}

In this study, hypotheses were formed within the framework of research questions. First of all, the basic research question (rq1) of this study is: 'Do the media messages have an effect on the development of a Defensive-Protective, critical or awareness-raising attitudes in Generation $\mathrm{Z}$ towards their position against online games?' Following this basic question, another research question (rq2) is as follows: 'Are online games (Blue Whale Challenge) the only reason for the suicide of young people? Finally, the last question ( $\mathrm{rq3}$ ) is: 'Do social differences have any effect on the interpretation of violence in the media content?'

The following hypotheses have been argued in this study in which the media content in different societies have been examined involving those news reports about the young people who committed suicide by harming themselves as a result of playing the game called Blue Whale Challenge:

h1: Some social realities as well as violence in the media content cause incidents of suicide in Generation Z.

h2: Different societies perceive violence in the media content in line with their own reality.

h3: Media content is effective in establishing the social perspective in line with Defensive-Protective, Critical, Awareness-Raising approaches.

Using the content analysis method, this study analyzed the news about young people who committed suicide by playing the game called Blue Whale Challenge in different parts of the world (e.g. Ukraine, India, the UK). While selecting these countries, the countries where suicide cases related to the Blue Whale game were experienced were searched through web search engine and the selections were made according to the news in the first countries at the time of the study. Also, this study aimed to analyze the relationship between the way the event is communicated through the media and social conditions. Additionally, another issue studied is the effect of the language used by the media on the formation of prejudices towards the game. The content descriptors of the Entertainment Software Rating Board (ESRB) were used for content analysis of news articles.

ESRB was founded in 1994 as a non-profit organization by the US Entertainment Software Foundation ESA. ESRB, which creates advertising 
guidelines and online privacy policies, also rates computer and video games. The aim of the organization is to inform and raise awareness in families about games and at the same time, to make the computer games sector accountable. ESRB carries out the rating in question as a result of the studies conducted with child development experts, academics, and parents. ESRB performs a classification process while rating. While symbols can be used in this classification, there are also evaluations performed under certain categories which are defined as "content descriptors" (Gürcan et al., 2008).

ESRB has been rating video games through rating symbols and content descriptors based on age groups so that game manufacturers can learn about consumer options. Content submitted to the ESRB by game manufacturers is independently rated by the evaluators (Haninger and Thompson, 2004). These content descriptors provide a more specific (e.g., age-based) ranking by explaining the game in detail. Through these content descriptors, game reviewers can evaluate whether the game is eligible. The ESRB also states that, apart from this assessment, it is also possible to achieve coding by making use of a more comprehensive listing for a particular game (Tocci, 2008). In this study, some selected content descriptors of ESRB and their explanations are stated as follows (ESRB, 2019):

Violence: Scenes involving aggressive conflict, bloodless fighting scenes.

Mild violence: Violent scenes with low intensity.

Intense violence: Realistic-looking depictions of death and scenes involving physical conflict.

Profanity: Use of profanity and vulgar language, obscene acts.

Among these content descriptors, the descriptors (violence, mild violence, intense violence, profanity) selected in accordance with the subject and scope of the study were identified as category criteria in the analysis of selected news articles.

Content analysis, which is frequently used in mass communication research, is used in the analysis of written, oral and visual documents. With this method, key themes are identified from the categorized and coded documents depending on the content (Wilson, 2011). The aim of this method is to analyze the trends reflected in the content examined. The news articles examined in the study were about suicide cases and determined by taking into account different countries.

In addition to the content descriptors of the ESRB, the language codes were also determined under the categories of Defensive-Protective and Critical and Awareness-Raising, which were classified under a specific group according to the content of the news articles. These codes were examined separately in each news article. Additionally, this study aimed to identify more clearly the incident-related approaches of the society in which the specific incidences occurred, through the categories and language codes under this group in consideration of the relationship between the two categorical criteria.

The coding units were identified under the analysis categories that convey the dimensions of interest in the content of the news. In the qualitative content analysis conducted within the scope of this research, it was aimed to determine the frequency of appearance and recurrence of the language codes under the specified 
categories in the news articles. The first categorical criteria and the language codes to be used in content analysis of news articles are given in Table 1.

Table 1. Category Criteria of ESRB and Language Codes in News Articles

\begin{tabular}{|l|c|}
\hline Category Criteria & Language Codes in News Articles \\
\hline Violence & Victim-deadly-terrible-tragedy-destructive \\
\hline Mild violence & $\mathrm{n} / \mathrm{a}$ \\
\hline Intense violence & Suicide-hang yourself-cut-toxic pill-drown in \\
\hline Profanity & $\mathrm{n} / \mathrm{a}$ \\
\hline
\end{tabular}

In the second part of the study, the language codes under different categories were determined in order to analyze the social approach towards the phenomena in the societies where the incidents subject to the news took place. The language codes in these categories and news articles are presented in Table 2.

Table 2. Category Criteria of Social Approach and Language Codes in News Articles

\begin{tabular}{|l|c|}
\hline Category Criteria & Language Codes in News Articles \\
\hline Defensive-Protective & $\begin{array}{c}\text { Detention-Police-Crime-Control-Ban-Sin-Blocking- } \\
\text { Censoring }\end{array}$ \\
\hline Critical & Questioning-Addiction-Suspect-Bad Intention \\
\hline Awareness-Raising & Awareness-Alert-Monitoring and Observation \\
\hline
\end{tabular}

The categories that explain the social point of view can be explained as follows:

Defensive-Protective: An approach towards isolation from harmful and aggressive content (Livingstone et al., 2005).

Critical: An approach towards analyzing, interpreting and criticizing how meanings are formed (Kellner and Share, 2005).

Awareness-Raising: An approach to taking measures or improving by analyzing positive and negative aspects.

While defining the criteria of this category, the literature on media literacy was reviewed as supporting data. The relevant news articles have revealed that the categories expressing the social approach somehow indicate the point of view towards the media content. Language codes under these 3 categories seem to prove the approach adopted in the creation of the media content.

According to this, the sources, titles and dates of the news selected from 3 different countries for analyses are as follows:

- Ukraine, Metro.co.uk-Metro Newspaper, "Girl 12, becomes youngest victim of Blue Whale "suicide game", 1 March 2018.

- India, The Indian Express, "Blue Whale Challenge? Girl commits suicide, 'cut here to exit' found written on her hand", 6 December 2018.

- UK, Daily Star, "Was young footballer's death one of 130 linked to 'Blue Whale' social media game?", 24 January 2018. 


\section{Results}

\section{Ukraine, "Girl 12, Becomes Youngest Victim of Blue Whale 'Suicide Game",}

According to the report dated 1 March 2018, a young girl named Anastasia Kysluk committed suicide by hanging herself. Laying emphasis on the game and calling it a 'Suicide Game', the report mentioned that she was the 'youngest victim of the game', and repeatedly stated that her mother was in Poland to work. It was emphasized that Anastasia, who lived with her grandparents, was a successful student based on the statements made by her teachers and classmates.

In the language codes complying with the categorical criteria of ESRB used in the news, the concepts of 'victim-lethal-scary-tragedy-suicide-suicide by hanging' are included under the category of violence. Anastasia, who was very successful in her classes, was described as a victim of the Blue Whale Challenge game.

Ranked among the top 10 countries, Ukraine has a quite high rate of suicide attempts. In recent years, the effect of social media and use of internet on suicide cases has been argued in Ukraine, where it has been asserted that suicide is promoted through these channels. The fact that one hundred children committed suicide in Ukraine in 2015 has drawn attention to the increase in suicide rates in children. Authorities hold the 'death groups' in social networks such as VKontakte, Facebook, Instagram, and Twitter responsible for the deaths. It was also identified that there were approximately 1000 death groups across social networks in December 2017. It was stated that young people aged 13-17 who committed suicide were vulnerable to the negative effects of social networks and had problems in communicating with others (Yaremko and Banakh, 2018). In this report, the vulnerability of the child who committed suicide was emphasized.

Among the categories for social perspective, the concepts of 'custody-crimepolice', which are among the language codes under the category of DefensiveProtective, have been used in the news article. These language codes refer to a protectionist approach involving the police protection of a child, who is shown as a victim, the investigation of the incident, and the detention of the suspects.

After the collapse of communism in 1991, the economic transformations in Russia had an extremely negative impact on the welfare of the population. The transition process in the countries, including Ukraine, caused the economic problems to be felt more intensely. These problems led to social psychological problems in life satisfaction and quality of life in these societies (Abbott and Sapsford, 2006). Another emphasis in the news article analyzed in this study is that Anastasia's mother was in Poland to work and provide her with a better life, while Anastasia had to live with her grandparents away from her mother. The language codes referring to economic insufficiency and the victim being defenseless reveal that the news article was created from a defensive-protectionist perspective. 


\section{India, The Indian Express, "Blue Whale Challenge? Girl Commits Suicide, 'Cut Here to Exit' Found Written on her Hand"}

The news article about a suicide case in India first gave information about the game, stating that a 17-year-old girl, whose name was hidden, committed suicide by hanging herself and wrote the phrase 'cut here to exit', inscribed on her hand with the help of a cutting tool. In the news article about suicide of the girl who liked to play mobile games, the language codes referring to concepts of cuttingcommitting suicide under the intense violence category were frequently used. Under the category of critical content, language codes referring to dependency and suspicion are also attention-taking in the content of the news article.

The incident in Nagpur in Maharashtra State, India's third largest city after Mumbai and Pune, could be interpreted according to the results of research on the impact of new technologies on young people in India (Pathak-Shelat and DeShano, 2014). The youth living in small towns and rural areas in India are still influenced by traditional social structures that shape their individual orientation. Apart from such a community with strong personal ties, the situation of young people living in larger cities is quite different. India's young population under the age of 25 constitutes almost $10 \%$ of the world population. India is also a country with deep and large structural divisions. It can be assumed that factors such as class, caste, gender, geographic location also affect the extent to which young people use the Internet. Internet experience of educated middle class students living in urban areas is quite different from those living in other regions (PathakShelat and DeShano, 2014). Since the news report underlined that the father of the young girl who committed suicide in Nagpur was a retired air force personnel, it can be considered as an example emphasizing the importance of economic discrepancies mentioned here. Her father's profession carried her to a superior economic class different from other young people. The fact that she was described as the child of an urban, middle class family in an economic sense distances her from the traditional structure in which young people in rural areas usually live. Additionally, the fact that she lived in the city with a better economic status compared to those living in the countryside caused her to be described as one of the young people living in cities and becoming lonely.

Another detail that draws attention in the news article is the emphasis on the academic failure of the young girl who committed suicide. As her college applications failed to be accepted, her father stated that she was unsuccessful. The news report mentioned her addiction to online games with a critical language. Therefore, the relationship between the suicide and online games should be reevaluated here. As emphasized in this study, there is no concrete evidence that online games directly cause suicide. As seen in this example, a variety of factors such as familial and psychological reasons appear to be influential on the suicide of the young girl.

In India, which attracts attention with its density in the young population between the ages of 15-30, it is stated that when the energy of this young population is not utilized sufficiently and efficiently, the acts of aggression and violence among youth increase (Tripathi, 2017). These violent actions include 
mocking, lying, encouraging coercive behavior, and repeated vulgarity. There is a significant gap in the country's legislation relevant to such issues. It is emphasized that legal arrangements should be made in addition to developing the technological infrastructure that is necessary for the prevention of violent acts that are experienced on the Internet (Tripathi, 2017).

Moreover, the critical perspective draws attention in the news article reporting a 17-year-old girl who is thought to have committed suicide under the influence of the Blue Whale Challenge in India. The girl's family referred to the games she had played on the internet as the cause of her suicide. The fact that the young girl was addicted to online games and had low academic success supports this critical point of view, but also shows that the relationship between online games and suicide should be evaluated together taking different factors into consideration as well.

\section{UK, Daily Star, "Was Young Footballer's Death One of 130 Linked to 'Blue Whale' Social Media Game?"}

Daily Star in the UK reported that a 15-year-old football team player, Jordan Moseley, committed suicide by hanging himself in his bedroom, adding that other young people were also claimed to have committed suicide before at different dates, because of online games. An important detail in the news article arises with the language codes used. For example, Blue Whale Challenge was defined as 'social network craze, experiment', and only the language code of 'bad faith' was found under the critical content category. Jordan's original cause of death was claimed to be an accident, considering that it would not be possible for a young and successful athlete to have committed suicide with everything he could have in his life. Here again, the game Blue Whale Challenge was presented as the only responsible factor. Such a perspective, however, ignores the fact that the boy who committed suicide may also have been affected by different factors as a member of a society.

The use of mobile phones is intense in the young population who use them to communicate through social media networks. It is clear that the Internet plays a significant role in the social and emotional development of the youth. Today, even parents now prefer to use technology to communicate with their children. On the other hand, socialization-communication, access to sound information and access to advanced learning opportunities are listed as the positive aspects of the Internet (O'Keeffe and Clarke-Pearson, 2011). Jordan's father said in his statement that there was correspondence with friends in his son's mobile phone, as usual, and that he did not encounter anything strange or unusual, which can be considered as an important detail in creating the perspective towards the incident.

The Report of Byron (2008), evaluates how children and young people are affected by social media and electronic media with respect to different age groups. In this report, it is stated that young people between the ages of 15 and 18, are still under the responsibility of their families. According to the report, young people in this age group want to have different experiences while they are under the responsibility of their families. Alcohol use or sexual experiences are desired especially during this period. Young people are particularly affected by the content 
they see in mass media. In a like manner, the news about Jordan reported that a responsible young person who had won the trust of his family lost his life in an experiment.

\section{Conclusions}

Based on the hypotheses of this study, Defensive-Protective, Critical, and Awareness-Raising approaches were observed in different dimensions in each of the news articles collected from the three different countries. When the news article about the incident in Ukraine is examined by taking h1 (h1: Some social realities as well as violence in the media content cause incidents of suicide in Generation Z) into consideration, it is clearly seen that the country has a social segment that suffered economic problems. In addition, the effect of this reality in suicide cases, which is common among young people in the country, is also indicated. In Ukraine, it is observed that there is a Defensive-Protective approach as a social perspective reflected in the news article. The effect of social realities can be observed in the approach to the events as stated in h2 (h2: Different societies perceive the violence in the media content in line with their own reality). The manner in which the text of the news has been created as mentioned in h3 (h3: Media content is effective in establishing the social perspective in line with Defensive-Protective, Critical as well as Awareness-Raising approaches), also has an effect on the adoption of such a protective approach. The news includes the language codes referring to the negative effects of the Internet and what a successful young girl went through.

Within the context of the social realities mentioned in h1, the news article about the incidence in India covers that there is a gap in the legal system which is underregulated in parallel with technological developments in the country. There are examples for the specific expressions of the different social realities conveyed in $\mathrm{h} 2$ through the language codes in which intense violence was clearly expressed. In addition, it can also be observed that the relevant language codes were used for a Critical approach in the construction of the news article.

The news story about the incident in England was constructed quite differently from those in the other three countries. Blue Whale Challenge, defined as 'social network craze', reflected a different social structure besides the conservative, protective, and stimulating approaches of the other three countries. Thus, the hypotheses $\mathrm{h} 1$ and $\mathrm{h} 2$ revealed a different reality in the case of England. An examination of the manner in which the news was created reveals the striking language codes used for the heroic death of a young person as a successful student and athlete who lost his life as a result of an accident while trying to conduct an experiment.

When the news articles are analyzed together with the assumptions put forward by this study, it is concluded that there are changes in the ways an online game is claimed to cause suicide of young people in societies with different living conditions, due to social differences. In more comprehensive studies on the subject, it will be useful to conduct a study to evaluate the structural origins of 
news sources and the comments of readers. The discussion of the subject within the framework of conservative-critical perspectives on media literacy will be an important step for the literature.

This study aimed to examine the structure of the media and online games that trigger violence as well as the role of media in reflecting people's overall perspective. In this context, the news articles constructed within the framework of different social realities were examined by content analysis method by taking examples from different countries of diverse geographies, including Ukraine, India and the UK in accordance with the categories of Defensive-Protective and Critical, Awareness-Raising.

As a result of this review, detailed evaluations have been made under Results and Discussion. However, if an evaluation is to be made according to the research questions and hypotheses determined in the study, the following conclusions will be reached:

- Media content has a profound impact on the way society views things. This impact sometimes even results in the emergence of a panic atmosphere.

- It is not right to come to a conclusion based on the assumption that online games alone lead to suicide.

- Some social conditions should also be considered as reasons leading to suicide.

- Just like the impact of social conditions on the process of creating media messages, social reactions are affected by media messages in a similar manner.

\section{References}

Abbott, P., Sapsford, R. (2006). Life-satisfaction in post-Soviet Russia and Ukraine. Journal of Happiness Studies, 7(2), 251-287.

Adeane, A. (2019). Blue Whale: what is the truth behind an online 'suicide challenge'? BBC Trending.

Alwin, D. F. (2002). Generations x, y and z: Are they changing America? Contexts, 1(4), 42-51.

Alwin, D. F., McCammon, R. J. (2003). Generations, cohorts, and social change. In Handbook of the Life Course, 23-49. Boston: Springer.

Anderson, C. A., Bushman, B. J. (2001). Effects of violent video games on aggressive behavior, aggressive cognition, aggressive affect, physiological arousal, and prosocial behavior: a meta-analytic review of the scientific literature. Psychological Science, 12(5), 353-359.

Bolton, R. N., Parasuraman, A., Hoefnagels, A., Migchels, N., Kabadayi, S., Gruber, T., et al. (2013). Understanding Generation $Y$ and their use of social media: a review and research agenda. Journal of Service Management, 24(3), 245-267.

Byron, T. (2008). Safer children in a digital world: the report of the Byron Review. Nottingham: DCSF Publications.

Daily Star (2018). Was young footballer's death one of 130 linked to 'Blue Whale' social media game? Daily Star. 
Drotner, K. (1999). Dangerous media? Panic discourses and dilemmas of modernity. Paedagogica Historica, 35(3), 593-619.

Entertainment Software Rating Board - ESRB (2019). Rating categories, content descriptive. ESRB.

Goldstein, J. (1998). Why we watch: the attractions of violent entertainment. NY: Oxford University Press.

Gürcan, A., Özhan, S., Uslu, R. (2008). Digital games and their effects on children. Ankara: Prime Ministry Family and Social Research General Directorate.

Hall, S. (2011). You've seen the movie, now play the game: Recoding the cinematic in digital media and virtual culture. Doctoral Dissertation. Ohio: Bowling Green State University.

Haninger, K., Thompson, K. M. (2004). Content and ratings of teen-rated video games. Jama, 291(7), 856-865.

Ho, C. H., Wu, T. Y. (2012). Factors affecting intent to purchase virtual goods in online games. International Journal of Electronic Business Management, 10(3), 204-212.

Hoon, K., Park, J. Y., Yul, K. D., Moon, H. L., Chun, H. C. (2002). E-lifestyle and motives to use online games. Irish Marketing Review, 15(2), 71-72.

Howe, N., Strauss W. (2000). Millennials rising the next great generation. New York: Vintage Books.

Hsiao, K. L., Lin, J. C., Wang, X. Y., Lu, H. P., Yu, H. (2015). Antecedents and consequences of trust in online product recommendations: an empirical study in social shopping. In A Focus on Consumer Behaviors and Experiences in an Online Shopping Environment, 77-99. UK: Emerald.

Huang, Y. C., Petrick, J. F. (2010). Generation Y's travel behaviors: a comparison with Baby Boomers and Generation X. Tourism and Generation Y, 1(Dec), 27-37.

Jorgensen, B. (2003). Baby Boomers, Generation X and Generation Y? Policy implications for defense forces in the modern era. Foresight, 5(4), 41-49.

Katz, S. (2017). Generation X: a critical sociological perspective. Generations Journal of the American Society in Aging, 41(3), 12-19.

Kellner, D., Share, J. (2005). Toward critical media literacy: core concepts, debates, organizations, and policy. Discourse: Studies in the Cultural Politics of Education, 26(3), 369-386.

Lindsay, J., Dill -Shackleford, K. E., Anderson, K. B., Bartholow, B. (2014). The proliferation of media violence and its economic underpinnings. In E. Douglas Gentile (ed.), Media Violence and Children, 1-44. US: Praeger.

Livingstone, S., Van Couvering, E., Thumim, N. (2005). Adult media literacy: a review of the research literature. London: Department of Media and Communications, London School of Economics and Political Science.

Metro.co.uk-Metro Newspaper (2018). Girl, 12, becomes youngest victim of Blue Whale 'suicide game'. Metro.co.uk-Metro Newspaper.

Mortensen, T. E. (2006). WoW is the new MUD: social gaming from text to video. Games and Culture, 1(4), 397-413.

Mukhra, R., Baryah, N., Krishan, K., Kanchan, T. (2017). 'Blue Whale challenge': a game or crime? Science and Engineering Ethics, 25(1): 285-291.

Nilsen, A. (2014). Cohort and generation: concepts in studies of social change from a life course perspective. Families, Relationships and Societies, 3(3), 475-479.

O'Keeffe, G. S., Clarke-Pearson, K. (2011). The impact of social media on children, adolescents, and families. Pediatrics, 127(4), 800-804.

Pathak-Shelat, M., DeShano, C. (2014). Digital youth cultures in small town and rural Gujarat, India. New Media \& Society, 16(6), 983-1001.

Potter, W. J. (1999). On media violence. UK: SAGE Publications. 
Przybylski, A. K., Ryan, R. M., Rigby, C. S. (2009). The motivating role of violence in video games. Personality and Social Psychology Bulletin, 35(2), 243-259.

Quwaider, M., Alabed, A., Duwairi, R. (2019). The impact of video games on the players behaviors: a survey. Procedia Computer Science, 151(2019), 575-582.

Sandeen, C. (2008). Boomers, Xers, and Millennials: who are they and what do they really want from continuing higher education? Continuing Higher Education Review, 72(Fall), 11-31.

Strauss, W., Howe, N. (1991). Generations: the history of America's future. New York, NY: William Morrow.

The Indian Express (2018). Blue Whale Challenge? Girl commits suicide, 'cut here to exit' found written on her hand. The Indian Express.

Tocci, J. (2008). Seeking truth in video game ratings: Content considerations for media regulation. International Journal of Communication, 2(26), 561-586.

Tripathi, V. (2017). Youth violence and social media. Journal of Social Sciences, 52(1-3), $1-7$.

Wang, H. Z., Sheng, J. R., Wang, J. L. (2019). The association between mobile game addiction and depression, social anxiety, and loneliness. Frontiers in Public Health, 7(Sep), 247.

Welch, M., Price, E. A., Yankey, N. (2002). Moral panic over youth violence: wilding and the manufacture of menace in the media. Youth \& Society, 34(1), 3-30.

Williams, D., \& Skoric, M. (2005). Internet fantasy violence: a test of aggression in an online game. Communication Monographs, 72(2), 217-233.

Wilson, V. (2011). Research methods: content analysis. In Evidence Based Library and Information Practice, 177-179.

Yang, Y. (2008). Social inequalities in happiness in the United States, 1972 to 2004: an age period-cohort analysis. American Sociological Review, 73(2), 204-226.

Yaremko, O., Banakh, S. (2018). Incitement to suicide with social networks and the internet: problems of criminal liability in Ukraine. In ACIT 2018, June 1-3, Czech Republic, 271-274. 
